\title{
Transformación en el paisaje de la comarca de Antequera (Málaga) durante el transcurso del siglo XV al siglo XVI
}

\author{
Transformation in the landscape of the region of Antequera (Málaga) \\ during the course of the 15 century to the 16 century
}

José Juan COBOS RODRÍGUEZ

"usted aprende

y usa lo aprendido

para volverse lentamente sabio"

(Currículum, M. Benedetti)

Author:

José Juan Cobos Rodríguez

Doctor en Historia Medieval

Profesor de Enseñanza Secundaria

Junta de Andalucía (Málaga, Spain)

muqtabis@yahoo.com

https://orcid.org/0000-0003-1616-3392

Date of reception: 11/03/21

Date of acceptance: 14/06/21

Citation:

Cobos Rodríguez, J. J. (2021). Transformación en el paisaje de la comarca de Antequera (Málaga) durante el transcurso del siglo XV al siglo XVI. Anales de la Universidad de Alicante. Historia Medieval, (22), 81-103.

https://doi.org/10.14198/medieval.19083

Acknowledgments: Agradezco a María Remedios Gómez Leiva la ayuda prestada en la traducción del resumen al inglés.

(C) 2021 José Juan Cobos Rodríguez

Licence: This work is licensed under a Creative Commons Attribution 4.0 International License (CC BY 4.0).

\section{RESUMEN}

La necesidad del ser humano de obtener más tierras de cultivo llevó a la transformación del paisaje natural de un sector central de la actual Andalucía a finales de la Edad Media, entre los siglos XV y XVI, como es la comarca de Antequera al norte de la provincia de Málaga (Andalucía, España). En este trabajo comprobamos, gracias a la documentación de archivo analizada, cómo este proceso afectó a una vegetación original (encina, alcornoque, matorral) y a una fauna salvaje (lobos, ciervos, tal vez osos) que fueron desapareciendo. Un monte mediterráneo, considerado en ocasiones un espacio de poco provecho, es el escenario donde se producen los cambios que lo convierten en tierras adecuadas para la explotación agrícola, dotadas, incluso, de agua. De este modo, un paisaje caracterizado por cierta diversidad natural pasará a ser humanizado, a ser dominado por la sociedad castellana de aquel momento, hasta lograr una imagen más uniforme del mismo. Un importante crecimiento de población llevó a que se realizaran diversos procesos de reparto de tierras que provocaron la transfor- 
mación del monte o bosque en espacios para el cultivo, después de un duro trabajo campesino. Sin embargo, este proceso no estuvo exento de polémica, con vecinos a favor y en contra de tales roturaciones sobre zonas que hasta entonces habían sido de aprovechamiento común.

PALABRAS CLAVE: Andalucía; Antequera (Málaga); explotación agrícola; fauna; paisaje; transformación.

\section{ABSTRACT:}

The human need to obtain more fields led to the transformation of the natural landscape of a central sector of the present-day Andalusia at the end of the Middle Ages, between the 15th and 16th centuries, such as the Antequera region to the north of the Malaga province (Andalusia, Spain). Through this paper we verify, mainly thanks to the analysed archive work, how this process affected an original vegetation (holm oak, cork oak, brushwood) and a savage fauna (wolves, deer and maybe bears) that gradually disappeared. A Mediterranean hill considered, on occasion, a little benefit area, is the scene where some changes, that turn it into suitable lands for agricultural production, even endowed with water, take place. This way, a landscape characterised by a certain natural diversity will be humanized, controlled by the Castilian society from that time, until it reaches a more uniform image from itself. An important population growth led to various land distribution processes that led to the transformation of the hill, or of the forest, into spaces for cultivation, after hard peasant work. However, this process was not without controversy, with neighbors in favor and against such breakings on areas that had been of collective use.

KEYWORDS: Andalusia; Antequera (Málaga); agricultural production; fauna; landscape; transformation.

\section{INTRODUCCIÓN ${ }^{1}$}

El Convenio de Florencia sobre el paisaje estableció que éste podía ser definido como "una parte del territorio tal como es percibido por la población, cuyo carácter resulta de la acción de factores naturales y/o humanos y de sus interrelaciones" (Cortina Ramos y Queralt, 2007, p. 38). Por ello, debemos de considerar el carácter dinámico del medio natural y la capacidad de poder ser transformado (Zoido Naranjo, 2011, p. 12).

1 Abreviaturas utilizadas: AACC: Actas Capitulares; AGS: Archivo General de Simancas; AHMA: Archivo Histórico Municipal de Antequera; CC-P: Cámara de Castilla, sección Pueblos; f. (ff.): folio (folios); LDR: Libro de Documentos Reales; leg.: legajo; LRA: Libro de Repartimientos de Antequera; p. (pp.): página (páginas); RGS: Registro General del Sello; s/f.: sin foliar. 
Diversos estudios han señalado que la forma distinta de organizarse de cada sociedad del pasado sobre un mismo espacio ha influido en la metamorfosis de su paisaje por medio de la actividad del ser humano, que deja su huella cuando adapta el entorno que encuentra a sus intereses y necesidades (Barceló, 1988; Buxó, 2006, García de Cortázar, 1988; Garrabou y Naredo, 2008; Kirchner, 2010; Malpica Cuello, 1996 y 2009). Tales investigaciones no dejan de señalar la importancia que posee el estudio de los paisajes históricos para conocer la evolución del territorio, siempre sobre la base de una metodología multidisciplinar, que nos acerque finalmente al conocimiento de la sociedad concreta que intervino en su transformación en un momento determinado de nuestro pasado.

Para advertir qué cambios se producen hay que partir de un paisaje previo, de época nazarí, conocido sobre todo por documentación posterior a la conquista cristiana, que nos devela puntos de continuidad y puntos de ruptura. El mundo rural en el reino de Granada (Trillo San José, 2004) se caracterizaba por su diversidad. El paisaje que conocen los castellanos se compone de una parte principal de espacios de regadío de trabajo intensivo ligados al hábitat, sea éste rural o urbano; un sector de tierras generalmente de secano tras ser vivificadas con su roturación para su puesta en cultivo; y otro de tierras comunales, que podían ser compartidas con vecinos de otras localidades. Será en estas tierras de uso común donde más claramente se pueda observar el cambio de paisaje, en espacios de monte y bosque antes no cultivados, que verán alterado en gran manera su papel dentro de la economía rural.

Nuestra intención en este trabajo es comprobar cómo se produce tal transformación a través de algunos de los elementos naturales del paisaje, como la flora, la fauna y el agua, en un territorio que actualmente se sitúa en la comarca andaluza de Antequera, al norte de Málaga, y que limita al este con Granada, al sur con Córdoba y al sudeste respecto con Sevilla. Tal sector fue centro de litigio por límites desde finales del siglo XV entre localidades de diferentes provincias, como la sevillana de Estepa, las malagueñas de Teba, Archidona y Antequera o las cordobesas de Priego, Benamejí e Iznájar, todas ellas localizadas en el área central de la actual comunidad autónoma de Andalucía (Alijo Hidalgo, 1983, pp. 128-129; Gozalbes Cravioto, 2015, p. 133). El aumento demográfico parece explicar que todos estos territorios iniciaran sucesivos pleitos en defensa de distintos intereses: ganado, madera o tierras para cultivo (Pérez Gallego, 1992, p. 28).

La información que analizamos, datada a partir de los últimos años del cuatrocientos, procede de distintos fondos archivísticos, como Actas Capitulares, Repartimientos, Ordenanzas municipales y Documentos Reales del Archivo Histórico Municipal de Antequera (Málaga), junto a otros documentos del Registro General del Sello y de la Sección Pueblos del Archivo General de Simancas (Valladolid). En todos ellos hallamos una temática común, la transformación del paisaje natural por 
medio de la apropiación de tierras que se van a destinar, sobre todo, a un aprovechamiento agrícola.

\section{2. "MONTES PARA HAZER ROÇAS"}

Tras la conquista castellana de la ciudad nazarí de Antequera en 1410 (Torres Fontes, 1972; Peláez Rovira, 2016, pp. 163-165), se va a desarrollar un largo proceso de reparto de tierras en consonancia con los intentos de repoblar un territorio que había sido vaciado de su población anterior. A lo largo de más de 80 años se suceden varias fases de repartimiento que culminará con lo que se conoció como la reformación, cuando los Reyes Católicos encargan al entonces corregidor de Málaga, Juan Alonso Serrano, que se ocupase de conocer el estado de las propiedades repartidas hasta ese momento y de realizar un nuevo reparto de tierras entre una población que desde entonces iba en aumento, entre otros cometidos. Todo ello aparece recogido en el Libro de Repartimientos de Antequera (Alijo Hidalgo, 1983), un complejo texto sin orden aparente, que muestra cómo se produjeron de forma oficial, es decir, con el beneplácito del poder real, las distintas fases de ampliación de las zonas de cultivo. Pero al mismo tiempo otros procesos, no tan reglados, fueron llevados a cabo por el cabildo de la ciudad y tildados en su momento de irregulares y arbitrarios ${ }^{2}$. De este modo se sobrepasó en mucho el primer repartimiento (iniciado en torno a 1414) al ir ampliándose el radio de la superficie a distribuir desde los sectores más cercanos al núcleo urbano hasta alcanzar los límites de su territorio, por medio de nuevas roturaciones sobre espacios dotados de una cubierta vegetal diversa y en pleno retroceso. Estos son señalados por la documentación como "montes", "tierras e montes", "sotos", "pedaços", "çerrillos", "montes e çerradas", "monte çerrado bravo" o "montes grandes" 3

De un modo u otro, los nuevos vecinos se asientan en la ciudad con la promesa de recibir un solar donde construir su vivienda y un lote de tierras para roturar ${ }^{4}$. A cambio, se comprometían a no vender ni enajenar sus nuevas propiedades y a poner en cultivo las parcelas concedidas en un plazo de 3 años, salvo aquéllas otorgadas por medio de una merced real, que podían roturarse cuando sus dueños lo estimasen 5 .

Terminados los primeros repartimientos, y ante la falta de espacios agrícolas, las siguientes zonas que van a ser esquilmadas para ello se hallan en los campos más

2 "el conçejo de la çibdad hazia repartimiento de las dichas tierras sin nuestro mandado, quitando a unos y dando a otros", AHMA, LRA, f. 5v.

3 Ejemplo de ello en AHMA, Ordenanzas, ff. 63v-65r; AHMA, LRA, ff. 2r y 234v; AHMA, LDR, ff. 46v-47v; AGS, CC-P, leg. 2, s/f.

4 "aquellos se an de medir e señalar en los montes brabos [en otro lugar, çerrados] fuera de lo medido", AHMA, LRA, f. 223v.

5 "aquellos que por merçed o enmienda de alguna cosa o vezindad se le oviere dado puedalo rasgar quando quisiere", AHMA, LRA, ff. 223rv. 
llanos de la vega, un sector tradicionalmente vinculado a zonas de cultivo, pero no de forma exclusiva, cuando, para entonces, encontramos en la misma terrenos que no habían sido roturados aún ${ }^{6}$, que incluso aparecen dotados de importante masa forestal ${ }^{7}$, o lo que algunos textos mencionan como "manchones", áreas destinadas al descanso de ganado de labor y que se situaban entre tierras dedicadas al regadío ${ }^{8}$. Algunas otras zonas boscosas habían quedado como lugares de separación entre los partidos en los que se había dividido el territorio durante los procesos de repartimiento realizados a lo largo del siglo $\mathrm{XV}^{9}$ y que funcionaban como ámbitos reservados para aprovechamiento comunal.

Tras la conquista, este tipo de espacios naturales se intentaron salvaguardar para el uso común, en calidad de tierras destinadas al beneficio de los vecinos de la población, de la comunidad, por mandato del monarca (Carmona Ruiz, 1995, pp. 60-61), y se referían a todo aquello entendido como propiedad no particular, áreas bajo la gestión del poder municipal y que no podían ser ocupadas (Luchía, 2005). Ni siquiera estaba permitido lucrarse con la venta de los recursos naturales que procedían de tales tierras, como establecía la regulación municipal al incluir "por común, espárrago e turma e cardo e tagurnina, esparto e yerva de hoçino e toda madera e alcarchofa e caça e lenna conforme a las hordenanças...e que en ningún tiempo lo puedan vender por cossa alguna" ${ }^{10}$. En otros documentos se señala de forma amplia que los vecinos podían hacer uso de los recursos contenidos en esos lugares "para los ganados", por ser "útile e provechoso...para pasto comund", al igual que el agua y la bellota de alcornoques y encinas para su alimento ${ }^{11}$, además de servir de cobijo o "manparo"12 a animales de todo tipo: bueyes, yeguas, ovejas o cerdos $^{13}$.

En el caso de la dehesa concejil que el cabildo municipal poseía para arrendarla a ganaderos foráneos, concretas "Condiçiones" limitaban su aprovechamiento, ya

6 "çien fanegas de monte para roças, las quales tomase en sus partidos de tierras...abajo de la Bega", AHMA, LRA, f. 97r.

7 Como "el chaparral que está en la Vega...en el rincón de la vega en medio de las aguas", el almendralejo o los carrascales, también señalados "en lo mejor" o "en medio de la vega", AGS, CC-P, leg. 2, s/f.

8 AHMA, Ordenanzas, f. 55r.

9 "monte çerrado...en el partido que dizen entre Herrera e Molina", AHMA, LRA, ff. 239v-240r.

10 AHMA, LRA, ff. 141v-142r y 222 r.

11 AHMA, AACC, f. 100v, sesión de 20 de septiembre de 1496.

12 "donde se guareçe al ynvierno"; "debaxo de las enzinas e álamos que el ganado puede muy bien pastar"; "de todos los bueyes de los vezinos en todo el tienpo del año"; "ay de yrvierno e de verano boyadas e yeguadas"; "e los pueden bien calar"; "sostienen de ynvierno aun de verano el ganado en ellas"; "donde se guareçe mucho el ganado de los veçinos en el ynvierno e en pro de neçesydad", AGS, CC-P, leg. 2, s/f. También las oquedades del terreno, como abrigos o cuevas, se utilizaban para el refugio del ganado: "La tercera cueva... llamase de Albacar, y es tan grande, que se suelen recojer en ella docientas vacas en tiempo de lluvias sin peligro de moharse" (TEJADA Y NAVA, siglo XVII, Capítulo IX).

13 Los cerdos debían pastar lejos de las tierras dedicadas al regadío por el daño que podían hacer en parcelas y acequias, AHMA, AACC, f. 83v, sesión de 24 de noviembre de 1495; AHMA, Ordenanzas, f. 53r 
que el arrendatario sólo podía disponer de la hierba para alimentar sus animales y de la madera necesaria para la construcción de chozas. El resto debía dejarse para beneficio de los vecinos ${ }^{14}$.

También eran ámbitos en los que los vecinos más pobres, necesitados y "menesterosos" encontraban su sustento por medio de actividades que realizaban para sobrevivir o como complemento en los periodos del año en el que no había trabajo (Clemente Ramos, 2014). Ejemplo de ello era la producción y venta de carbón vegetal ${ }^{15}$, la caza sin permiso ${ }^{16}$ o el cultivo de cereal que se osaba practicar en espacios no permitidos, como veredas, vados y baldíos ${ }^{17}$.

La labor del cabildo de la ciudad tendía a la protección de esos bienes comunales, sobre todo ante la mala praxis en la que caían algunos vecinos a la hora de su explotación ${ }^{18}$. Así mismo, se observa la especial atención señalada en algunas concesiones de tierra en favor de conservar el área arbórea que pudieran contener: "dadselas señaladamente en las tierras y heredades del rincón de Herrera con los árboles que en ella obiere sin se los cortar ni quitar". En relación a ello, en 1496 el reformador del repartimiento estableció una serie de condiciones a la hora de dar "montes para roças" con el objeto de proteger el aprovechamiento común ${ }^{19}$.

Sin embargo, pronto se alteró la obligación de no ocupar los terrenos de uso comunal. Si en el primer repartimiento se indicaba que "quedan reservadas las baderas y beredas, rodeos y cannadas e abrebaderos como quedan sennalados para el usso e pro común de todos los vezinos", ya en la segunda fase (desde 1438), el entonces alcaide:

no repartió las tierras e cavallerías según devía, antes diz que las repartió por pedaços dando mayores cantidades que el dicho su padre dava, e que aquella causa algunos veçinos de la dicha çibdad avian entrado e tomado muchas tierras que quedaron realengas, baldías que no se avian repartido ${ }^{20}$.

Al crecer la necesidad de áreas que cultivar, los "montes públicos", que en principio tenían un destino silvicultor para el bien de los vecinos en los momentos que necesitaran madera, corcho o cazar, van a pasar a tener un uso privado con cada nuevo proceso de roturación. El destino de estas nuevas tierras era dedicarlas prin-

14 Así ocurre con la denominada Dehesa de la Cuevas que era ofrecida a ganaderos sobre todo de localidades sevillanas y cordobesas, "quedando a salvo toda madera, de monte o de río, o otra qualquier madera e esparto y villota e caça", AHMA, AACC, f. sesión de 22 de agosto de 1494.

15 "por ser él onbre neçesitado y porque la çibdad sea proveyda", AHMA, AACC, f. 22v, sesión de 18 de agosto de 1495.

16 AHMA, AACC, f. 10r, sesión de 4 de febrero de 1494.

17 AHMA, AACC, f. 129r, sesión de 23 de mayo de 1497; "que es cosa esas roças para los pobres en que mucho se remedian", AGS, CC-P, leg. 2, s/f.

18 Se denuncia que "para cortar una carga de leña cortavan un enzina por el pie", AHMA, AACC, f. 58v, sesión de 24 de marzo de 1495 .

19 Ambas referencias en AHMA, LRA, ff. 57r y 234r.

20 AHMA, LRA, ff. 2r y 107 r. 
cipalmente a "senbrar pan", cereal, aunque también hay espacios que en principio se destinaron al cultivo de la uva, con majuelos y viñas nuevas ${ }^{21}$. De esta manera las tierras del monte pasaban a tener utilidad agraria para tareas como la labranza, la siembra, alimentar al ganado tras la cosecha ${ }^{22}$ o el "quemar los montes", actividades que no habían sido posibles de realizar hasta entonces ante la "bravería y espesura" del terreno ${ }^{23}$.

Los modelos de títulos de concesión que recogen los Repartimientos hacen ver también que los vecinos podían dedicar los nuevos terrenos a establecer molinos, colmenares, tejares, casas o ventas ${ }^{24}$, a condición de no desprenderse de la nueva propiedad, bajo pena de perderla. Así comprobamos que son múltiples las actividades que se fomentan en las zonas que iban ganándose al monte: agrícolas, ganaderas, artesanas o de servicios ${ }^{25}$.

El crecimiento de población que va a conocer la ciudad desde la última década del siglo XV no se interrumpe en las primeras décadas de la siguiente centuria hasta convertirse Antequera y su territorio en uno de los lugares más poblados de España en el siglo XVI (Parejo, 2002, pp. 19-21). Ello provocó que, ya finalizada la reformación, aumentase la necesidad de nuevas tierras y al mismo tiempo la presión sobre los montes (Luchía, 2020, p. 325), un nuevo proceso que ya no recoge el Libro de Repartimientos. En algunos casos, ciertos pobladores se habían quedado fuera del reparto ${ }^{26}$ y en otros, el "poco término para labrar para pan" se aduce como motivo para realizar nuevas rozas en "otros muchos montes" ${ }^{27}$. Si en un primer momento las tierras a desmontar, como hemos señalado, se dedican a cereal y viña, ya en las tierras para rozar a inicios del siglo XVI aparecen destinadas casi de forma exclusiva a cereal.

En este sentido, un revelador documento para el tema en cuestión, a lo largo de unos 20 folios y fechado en el verano de 1515, hace ver que tal aumento demográfico ${ }^{28}$ lleva a la necesidad de ampliar las zonas de cultivo, la base del trabajo campesino, porque, como varios vecinos atestiguan, "no ay tierras las que basten para los vezinos e alguno se va a labrar a lugar de señoríos por falta de tierras" ${ }^{\prime 2}$. Por ello,

21 AHMA, LRA, ff. 169v-171r y AACC, f. 59v, sesión de 7 de abril de 1495.

22 Los primeros nueve días se destinaban al ganado del dueño de la tierra, AHMA, Ordenanzas, ff. 50v-51v.

23 AHMA, LDR, ff. 66v-67r. AGS, CC-P, leg. 2, s/f.: "alçando el fruto, syrven de pasto".

24 Para ello se permitía cortar "toda la madera asy para faser e edificar la dicha venta como para quemar en ella...de los montes públicos e labrar la tierra que fuere menester para labrar e senbrar vuestro pan e para faser una huerta", AGS, RGS, 148704, 14.

25 AHMA, LRA, ff. 169v-172r.

26 "pareçió que algunas personas no yban probeydos e otros pedian de nuevo tierras e solares e montes e otras cossas", AHMA, LRA, f. 216r.

27 Los fragmentos de texto recogidos a continuación pertenecen a AGS, CC-P, leg. 2, s/f.

28 "porque como esta çiudad ha creçido en vecindad, ay mucha neçesydad de las dichas roças".

29 Testimonios similares reflejan la misma problemática: "que sy más roças se hiziesen, avía donde senbrar más e donde se estendiesen los labradores e comiesen los ganados, porque ay poco término e los labradores se van fuera del término a labrar e los ganados a ervajar"; "ve e ay muchos vezinos que van a labrar fuera del termino e sy oviesen roças travajarian en lo suyo". 
terminada la reformación del bachiller Serrano en la última década del siglo XV, es el momento para que el cabildo local fuera concediendo nuevos terrenos para roturar.

Sin embargo, la acción del poder municipal de permitir la roturación en determinados espacios naturales terminó por provocar que algunos vecinos acudieran a la corte a denunciar la destrucción de lo que consideraban zonas de aprovechamiento para la comunidad. Gracias a ello, se comprueba la existencia de posturas contrapuestas, como puede leerse a través de diversos testimonios recogidos en el mencionado documento y que aportan un destacado volumen de información.

Unos vecinos son presentados como testigos conocedores de las tierras por un jurado del cabildo ${ }^{30}$ y otros son convocados por el personero ${ }^{31}$ que representa a la "comunidad" 32 . Todos ellos responden por separado a similares interrogatorios con el objetivo de: averiguar qué zonas fueron consideradas aptas para roturar; qué necesidad existió para hacerlo; qué beneficio se había obtenido con ello, respecto al esfuerzo empleado por sus propietarios; y, sobre todo, qué tierras fueron roturadas de forma conveniente y cuáles no debieron haberse concedido nunca. Las respuestas no difieren mucho entre los dos grupos de testigos, aunque notamos que al primero de ellos les preocupaba el estado de inseguridad de determinadas tierras antes de que fueran roturadas, mientras que el segundo grupo mostraba más inquietud por la pérdida de lugares destinados al ganado.

De todo ello parece deducirse que el cabildo local se había excedido en la entrega de tierras para roturar sin el permiso pertinente del poder regio ${ }^{33}$, irregularidades que, como hemos señalado más arriba, ya habían sucedido durante el siglo XV. En esta ocasión el regimiento de la ciudad se escudaba en considerar que eran "montes bravos e syn provecho y donde no ay agua correntía", "montes perdidos" e incluso "sequedales" ${ }^{34}$, pero que eran zonas ideales para convertirlas en nuevos espacios para el cereal, donde se "coxe más pan"35. La mayor parte de testimonios confirman el nulo aprovechamiento de algunas de las tierras que se concedieron, señalando a lo sumo que podían servir de pasto para cierto tipo de ganado menor: "no es de ningund provecho para cosa ninguna, syno para cabras, e aun todo ello no es bueno para cabras" ${ }^{36}$.

30 "yo me ynformé particularmente de personas antiguas e sabidores".

31 Sobre este representante del común en Castilla (Rodríguez Molina, 2003).

32 En algún caso se refleja el bajo nivel cultural de los testigos del común: "no lo firmó porque no sabía fyrmar".

33 "las roças que se an dado tras la syerra pareçe e se averigua que ha sydo en deserviçio de vuestra alteza y en perjuyzio de la vezindad de esta çiudad por ser la tierra dispuesta e gruesa para los ganados"; "las roças que allí se an dado a sydo de mucho perjuyzio". Tras el interrogatorio se comprueba que la reina había sido "deservida en lo que se a dado".

34 En otro punto se señala que "ninguna agua tiene que corra ni que mane".

35 Un proceso similar hallamos para el siglo XVI en términos de la ciudad de Málaga, donde se rotura zona de bosque con el fin de aumentar la superficie destinada a la vid, cuya producción era orientada al comercio exterior (Gómez Moreno, 1989, p. 248).

36 A ello se suma que "los ganados se aprovechan muy poco". 
De la lectura del documento que aquí seguimos, se desprende la existencia de dos áreas muy distintas, claramente definibles en el paisaje por la línea que sirve de separación entre ambas y que es constituida por una destacada vía fluvial que hallamos a $4 \mathrm{kms}$. al norte de la actual ciudad de Antequera y que cruza su vega de este a oeste, el río Guadalhorce: "la çiudad a dado asy de aquel cabo del río de Guadalhorze como hazia la parte de la syerra, que a visto hartas roças de ellas". Un primer sector lo forman tierras situadas al norte de la línea señalada hasta alcanzar otra corriente de agua, el río Genil, a $20 \mathrm{kms}$ de la ciudad. Responde a un paisaje de monte bajo ${ }^{37}$ ("los dichos montes no son de madera"), difícil de transitar ("que no se puede hender", montes "muy çerrados"), caracterizado por considerarse tierras inútiles ("por ser como es tierra esterile e syn fruto"), pero con gran potencialidad agrícola $^{38}$. Se trataba de un espacio con un relieve de suaves lomas que tienden a lo llano, sin fuertes pendientes, y tal como lo indica algún vecino "son como canpiñas". Una referencia a esta zona ya roturada la hallamos más tarde en un texto del siglo XVIII: "Después de haber atravesado grandes barrizales pelados y tierras buenas para granos, se pasa el río Guadalhorce" (Ponz, 1989, p. 764).

Además, era el sector que más preocupación daba a los vecinos. La transformación de los montes no sólo se produce con la intención de obtener cierto beneficio económico, sino también por acabar con un destacado foco de inseguridad, ya que servía de refugio al bandidaje ("aunque vaya gente en pos de ellos non los hallaran"), en unas tierras consideradas para "daño de ladrones" o "salteadores", que "estavan muy peligrosas e aparejados para saltear ladrones" y donde "se podrían esconder en ellos malhechores e estando rasos e aconpañados de gentes estarán más seguros". Así, conocemos que eran áreas de paso para quienes frecuentaban los caminos que salían de la ciudad en dirección norte, especialmente inseguras, si se viajaba sin compañía a la hora de atravesar tierras que guardaban huellas de los hechos criminales cometidos a su paso ${ }^{39}$. Precisamente esas vías de comunicación se muestran como los ejes a partir de los cuales se realiza la distribución de las parcelas más favorables a ser roturadas ${ }^{40}$, a diferencia de otras zonas más alejadas de los caminos, que coinciden con los terrenos más frondosos que los vecinos no quieren ver roturados.

37 "espeçialmente los términos que están de aquella parte del río de Guadalhorze e los otros donde están señalados lugares e parte".

38 "todos los otros montes que están del Guadalhorze aquel cabo hazia la parte de GuadalXenil es muy útil e provechoso, que se reparta por roças a los vezinos de esta çiudad"; "la çibdad a dado hartas roças para rasgar e coger pan en este término de aquel cabo de Guadalhorze hazia el Almendralejo, a la Laguna Salada, camino de Luçena".

39 "ay mataron un onbre e se fue a la justiçia por los montes e que camino de los Ojos e en otras partes ay mojones e señales de personas que an muerto por los caminos"; "ay otros hartos montes camino de Luçena e camino de Santaella e en hartas partes que ay aparejo para se esconder ladrones en ellos son montes çerrados".

40 "se an dado orilla de los caminos»; "algunos montes ay bravos e çerca de caminos reales". 
Así parece defenderlo la comunidad, cuando se considera que las roturaciones a discreción permitidas por el poder local habían llegado a no respetar sectores con una capacidad arbórea importante: "guardando el chaparral y el enzinar de los Ojos de Güécar e la cañada del Almendro, porque esto sería muy dañoso sy se repartiese a los vezinos". Son aquellas áreas de las que los vecinos, al contrario de lo considerado para las tierras mencionadas más arriba, sí se podían ver beneficiados, si se mantenían intactas, "porque son montes provechosos", ya que "todos con sus ganados comen en ellos e cortan madera".

Por otro lado, donde la vegetación aún va a ser más valorada por su variedad y su aprovechamiento, será en los extensos espacios situados al sur del Guadalhorce en dirección a las sierras que cierran la depresión antequerana por su sector meridional, "montes muy altos" con características totalmente contrarias a los términos roturados en la zona ya señalada, al mencionarse como "monte muy provechoso" La existencia de agua y la marcada fertilidad de estas tierras ("tras la syerra son montes donde ay agua e pasto") llevan a que los vecinos pidan su protección y, por tanto, se opongan totalmente a su destino para rozas con expresiones como "no se deve repartir cosa ninguna", "no se deve dar roça ninguna", "que en ella no se dé cosa ninguna para roças" o "no son para dar". De esta manera, la pérdida de la riqueza de estas zonas, "por ser la dicha tierra fuerte e de mucha agua e madera e vellota e corchos, corteza e otras cosas", se concibe por parte de la población local como perjudicial, respecto al aprovechamiento que hasta ahora se venía disfrutando:

las dichas roças que se an dado de esta parte de Guadalhorze y en la Syerra para senbrar pan son perjudiçiales e de abellas dado viene mucho perjuyzio a esta çiudad e vezinos e moradores de ella e a los ganados, por ser como es la dicha tierra de esa parte de Guadalhorze muy gruesa e provechosa para los dichos ganados e la leña que en los dichos montes se cría buena para serviçio de los vezinos ${ }^{42}$.

Un documento de 1495, veinte años antes de estas denuncias vecinales, muestra cómo el cabildo municipal ya trató de prohibir los trabajos agrícolas en determinados lugares en este mismo sector sur: "de aquí adelante no se a de dar roça tras la syerra" "33. Sin embargo, como comprobamos, la necesidad de más tierras de cultivo llevó a la ciudad, con el tiempo, a permitir nuevas roturaciones en esa misma área.

41 "y en lo que toca a los montes e tierras que están de Guadalhorze a esta parte hazia la syerra, asy de este cabo como de aquel cabo de la dicha syerra, no se deve repartir cosa ninguna se para roçar porque los dichos montes e tierras son tierras fértiles, gruesas de mucha agua".

42 En otros pasajes se insiste en que "es mucho perjuyzio, porque las an dado en partes donde ay agua e ay montes que se pueden muy bien pastar e tierras de que los vezinos se pueden muy bien aprovechar"; "provechosos para madera e carretas e para ganados, que debaxo de las enzinas e alamos que el ganado puede muy bien pastar espeçialmente en lo que se vio hazia alcornocal e en barias partes tras la syerra e por esto son perjudiçiales las roças que se dieran tras la syerra".

43 Sobre todo en los alcornocales, AHMA, AACC, f. 36r, sesión de 3 de febrero de 1495. 
Otra cuestión, que se nos muestra transparente a la luz del documento de 1515 que estamos comentando, se refiere a los duros trabajos que los campesinos debían realizar para lograr poner en cultivo (en "cultura") las distintas tierras concedidas. Estas labores incluían limpiar de vegetación y piedra el terreno, allanarlo, reducir su pendiente, drenarlo donde fuese necesario o buscar agua, en definitiva poder lograr una superficie útil. Todo ello queda reflejado en la variada terminología utilizada en la documentación para referirse a esa roturación de los montes. El verbo más común es el de "desmontar", en alusión a la tala de árboles y limpieza de matorrales, pero con un significado similar podemos encontrar otros como "roçar", "rasgar", "alçar", "ronper", "enxerir"44, además de "enrasar", "arrasar", "meter en labor" o simplemente "labrar". Así, el objetivo último era preparar la tierra para el trabajo agrícola: "hazer tierras de labor" 45 , "tierras de pan llevar" o "tierras de montes para desmontar e fazer tierras de labor".

Tales labores implicaban una fuerte inversión para los vecinos ocupados en ellas, incluso cayendo en la ruina, como señalan algunos testimonios"6: "las personas a quien se an dado las dichas suertes para hazer las dichas roças an gastado mucha parte de sus haziendas en desmontar, allanar e despedregar...más que las dichas tierras valen" ${ }^{47}$. El alto coste era claro, pero iba más allá de una cuestión monetaria. Las palabras de los vecinos expresan que las faenas a realizar en el campo eran extenuantes, que incluso implicaban la pérdida de los medios de trabajo animal: "porque an gastado e travajado e muerto bueyes para los abrir" 48 . Tan duro parecía la tarea a acometer, que determinados propietarios tuvieron dificultades para contratar a trabajadores que pudieran y aceptaran realizar las labores necesarias: "dan por cada hanega de desmontar un ducado e aún dos en lo muy bravo e que se tomase la leña, e non lo quisyeron fazer".

Por ello, se antojaba que todas las zonas concedidas no eran fáciles de transformar, aún más si cabe, cuando en ocasiones eran áreas muy en relación con la existencia de aguas lacustres, que había que desecar para poner en cultivo, labor que resultaba vana en los momentos en las que puntuales y excesivas precipitaciones volvían a inutilizar la tierra (Tejada Páez, 2005, p. 182). Esto ocurría en distintas partes del término de Antequera, como en las Lagunillas, al sudeste de la ciudad ${ }^{49}$, en "el agua

\footnotetext{
44 Este término lo leemos en AHMA, LRA, f. 234r.

45 AHMA, LRA, ff. 239v-240r.

46 "e personas ay que han fecho roças e se an perdido e quedan destruydos de ellos", de nuevo, como las siguientes, en AGS, CC-P, leg. 2, s/f.

47 "en una roça que ha fecho, a gastado mas de çient mill maravedis e no vale çinquenta mill maravedis lo que a fecho".

48 "gastan más que valen las tierras e matan sus bueyes".

49 "las roças que se an dado en el partido de las Lagunillas tanbien son muy perjudiçiales porque la dicha tierra no es buena para pan", AGS, CC-P, leg. 2, s/f. En este sector se consideraba que "los montes e chaparrales son muy flacos e de poco provecho", AHMA, Ordenanzas, f. 66v.
} 
de Santillán e Fuente la Piedra" ${ }^{50}$, al noroeste, pertenecientes actualmente a los municipios de Mollina y de Fuente de Piedra, o en las aguas de Herrera ${ }^{51}$, hoy tierras de cultivo que se extienden en la zona norte, más allá del río Guadalhorce.

En suma, a pesar de las quejas vecinales ante la destrucción de puntos claves para el beneficio de la comunidad, volver atrás ya era imposible. La transformación del entorno natural supuso un proceso irreversible, y de ello eran conscientes los propios vecinos, como puede comprobarse por medio de los testimonios aporta$\operatorname{dos}^{52}$. De ahí que, terminadas las necesarias averiguaciones, se solicitase a la reina doña Juana la aprobación de las licencias de roturación concedidas por el cabildo de Antequera. Además, así mismo se obtenía el beneplácito real para continuar con futuras roturaciones, en esta ocasión, en tierras que verdaderamente "no aprovecha a ninguna cosa" 53 .

De este modo, la múltiple función del monte a finales de la Edad Media (aprovechamiento forestal, reserva de tierra para cultivar, evitar el peligro de alimañas a las poblaciones, permitir el pasto del ganado o capa protectora para las frágiles áreas irrigadas, Malpica Cuello, 2000, pp. 148-149) se vio alterada por la necesidad de los castellanos de nuevas tierras que cultivar, en terrenos que nunca se habían dedicado antes a terreno de labor ${ }^{54}$.

\section{LA VEGETACIÓN PERDIDA}

En un clásico trabajo, pero de obligada consulta, sobre la depresión malagueña de Antequera, ya se señalaba que la vegetación climácica había casi desaparecido en las zonas más llanas y se hallaba muy degradada en las más elevadas (Guarnido Olmedo, 1977, p. 49). Para entonces, se hacía alusión a especies arbóreas típicas del bosque mediterráneo, como el pino carrasco, la encina y sus variantes (como el chaparro o la carrasca), el alcornoque y el acebuche, que aún se podían hallar de forma residual y periférica. La instantánea que sobre la vegetación recogía tal estudio no era muy diferente a la imagen que podemos encontrar en los momentos actuales, cuando tales áreas boscosas prácticamente no existen en el entorno de la vega antequerana y en

50 Un vecino concreta que la zona ahora roturada se dejó como baldío en la reformación del bachiller Serrano, "desde el agua e su rodeo los juncales abaxo e desde allí el camino abaxo sobre la mano ysquierda hasta abajo del Algarvejo", AGS, CC-P, leg. 2, s/f.

51 Sector que era considerado de "mala tierra", AHMA, LRA, f. 164r.

52 "sy a los que han dado las roças se las quitasen, çierto reçibirían mucho daño e perjuyzio"; "sy agora ge lo quitase, era dexallos destruydos y echados a perder"; "e que sy los quitasen a los que los tienen mucho perjuyzio les sería, porque an gastado más que vale las tierras”, AGS, CC-P, leg. 2, s/f.

53 Mientras que las tierras "que están por dar, vuestra alteza deve mandar dar liçençia e facultad para que se puedan dar", las situadas al sur, en dirección a la sierra, "vuestra alteza deve mandar que no se den las dichas roças ni se ronpan las dichas tierras", Ibidem.

54 Procesos similares se han estudiado para el reino de Granada (Malpica Cuello, 1993, p. 543) y para el Levante peninsular (Torró, 2003, pp. 174-181). 
las zonas más montuosas muchas de las especies mediterráneas han sido sustituidas por otras, generalmente coníferas, por medio de la reforestación (Rodrigo Comino, 2014, pp. 69-78 y 151-153). Las especies mencionadas formarían lo que podríamos denominar la vegetación tipo de tales tierras, relacionadas con un ecosistema muy definido de carácter mediterráneo. Todo ello responde a un proceso histórico de replegamiento vegetal que ha conocido distintas etapas a lo largo del tiempo ${ }^{55}$, siendo el que estamos mostrando en este estudio uno más de sus episodios ${ }^{56}$.

La cubierta vegetal que aparece en las tierras que se rozaban para cultivo durante los últimos tiempos medievales destacaba por su variedad y se puede disponer en dos grandes grupos. De forma clara se distinguen los espacios de monte bajo, respecto a los de ámbito forestal, dotados éstos de una masa arbórea uniforme ${ }^{57}$. Por un lado, hallamos cierta vegetación que es considerada reiteradamente de escaso provecho, de matorral en gran parte. Se caracteriza por presentar "espesos xarales e madroñales e çaguançales" 58; "romerales, espartales, syn provecho ninguno, asy para ganado como para leña por ser como es tierra estérile e syn fruto"; coscojales, "tañizares" 59 , lentiscos "e de otras fustas syn provecho" 60 . Todo ello corresponde con aquellas zonas naturales elegidas como las más aptas para ser arrasadas y ponerlas en cultivo. Por las especies señaladas, estamos ante un sector natural que contaba con un medio mediterráneo degradado y con suelos de escaso espesor, donde la característica más patente es la ausencia de árboles (Rodrigo Comino, 2014, p. 74).

Por otro lado, se hace referencia a montes dominados por especies forestales propias del bosque mediterráneo (Trillo San José, 1999) no distribuidas de forma dispersa, sino concentradas en determinados lugares y que la documentación recoge en forma de sustantivos colectivos y a menudo, además, en plural. Así sucede con la encina, el chaparro, la carrasca, el quejigo, el alcornoque, el acebuche, en menor

55 Desde los primeros cambios realizados por las poblaciones neolíticas, como refleja el único estudio coral que ha incidido en la transformación del paisaje en el pasado de la zona (Caballero Sánchez, 2011).

56 Falta aún por hacer un análisis diacrónico y multidisciplinar que sume datos procedentes de diversos documentos para trazar con mayor exactitud la evolución del paisaje natural a lo largo de los últimos siglos. Ejemplo de ello sería el Catastro de Ensenada, que a mediados del siglo XVIII proporciona una estampa fija en ese momento al mostrar ya la disposición dispersa de las especies arbóreas mediterráneas en la zona (Fernández Paradas, 2004, p. 344).

57 Sea bosque o monte son espacios mencionados de forma muy genérica en la documentación (Trillo San José, 1999, p. 131) e incluso menospreciados por los análisis históricos (García Latorre y García Latorre, 1996).

58 Zagua: arbusto similar a la barrilla de la que se extrae la sosa, del árabe sawda (Blanca López, 2009, p. 176).

59 Aunque podría leerse cañizares, sin conocer el área exacta de la que habla el documento y ante la necesidad de agua para que estos aparezcan, podemos apuntar la posibilidad de que se trate de un lugar poblado de taños, vocablo muy en relación con el proceso del curtido de pieles, labor artesanal de destacado desarrollo en la zona (Pérez Gallego, 1992, pp. 48-52).

60 AGS, CC-P, leg. 2, s/f. 
medida el enebro, y también con vegetación de ribera como el álamo o el fresno ${ }^{61}$. A todos estos tipos de árboles podríamos añadir el almendro, presente en espacios no cultivados $^{62}$. Se trata de todas las especies que forman arboledas y que son objetivo de las roturaciones permitidas por el cabildo, a pesar de hallarse en áreas consideradas por los vecinos de importante uso común, por lo que sufren un paulatino retroceso al ritmo del aumento de las concesiones de tierras para convertirlas en cultivo.

El principal aprovechamiento relacionado con tal variedad de especies arbóreas, y que resaltan los textos estudiados, es la obtención de madera, actividad que afectaba a todo tipo de arboleda "de monte o de río"63. La salvedad la hallamos en ciertas variedades cuya tala se prohíbe, como las señaladas por los documentos como "canperas", en referencia a determinados espacios de encinas y fresnos, aunque también en ocasiones se vetaba cortar determinados alcornoques, acebuches, quejigos y almendros ${ }^{64}$. El destino de la madera era muy diverso. Podía usarse como leña para combustible ${ }^{65}$, para la construcción de viviendas o de puentes, para realizar distintos componentes de arados o de molinos, y como base para recipientes domésticos como dornillos y escudillas ${ }^{66}$.

Llama la atención el dato de que, durante el momento mismo de la conquista en 1410, distintas máquinas de asalto, como las bastidas, no fueran construidas in situ con madera del entorno, como sí ocurrió en otros asedios, lo que puede explicarse por la escasez o ausencia en el entorno de especies como el pino o el castaño ${ }^{67}$. A pesar de ello, lo que podemos comprobar es que, durante el espacio temporal estudiado, la explotación de la madera aparece como una destacada actividad para numerosas localidades vecinas. Esto queda reflejado, por ejemplo, en los litigios que involucran a varias localidades, como Antequera, Estepa, Benamejí o Archidona, cuando quieren apropiarse de forma exclusiva de áreas forestales que en otro tiempo sus pobladores pudieron gozar de forma compartida ${ }^{68}$. Sin embargo, el radio de

61 Como los álamos que se talan en el entorno del río Genil o las referencias a la alameda del Espino, Alameda Blanca o Alamedilla AHMA, LRA, ff. 15v, 17r, 154r, 236; AHMA, AACC, f. 83r, sesiones de 13 de noviembre de 1495 y f. 101v, 7 de marzo de 1497; AGS, RGS, 150012, 163; y AGS, CC-P, leg. 2, s/f.

62 Sobre su forma asilvestrada en Andalucía (Blanca López, 2009, 3, p. 43).

63 AHMA, AACC, f. 22v, sesión de 22 de agosto de 1494

64 El cabildo recomendaba realizar la tala "en monte çerrado", AHMA, AACC, f. 87v, sesión de 4 de diciembre de 1495; el acebuche estaba especialmente afectado por la acción de los pastores, f. 83v, sesión de 24 de noviembre de 1495; se prohíbe la tala de estas especies en AHMA, Ordenanzas, ff. 63r-64v.

65 Cuando sólo tenían permiso para cargas de leña seca, algunos vecinos se sobrepasaban al cortar encinas y chaparros por el pie, AHMA, AACC, f. 58v, sesión de 24 de marzo de 1495.

66 AHMA, AACC, f. 58v, 24 de marzo de 1495; f. 83r, sesión de 13 de noviembre de 1495; en diversas cartas de enero de 1496 en una sesión sin fecha, f. 78; y en f. 127r de diciembre de este último año.

67 Como en el caso de Setenil, Cádiz, (García de Santamaría, 1982, p. 174); sobre las bastidas realizadas en Sevilla (Ibidem, pp. 298 y 378); sobre el envío de madera de pino durante el asedio a la ciudad nazarí de Antequera, (Ibidem, p. 320).

68 "os çerteficamos que esta çibdad tiene tan talados sus términos de los vesinos comarcanos y otras personas”, AHMA, AACC, f. 95v, sesión de 23 de enero de 1496; (Pérez Gallego, 1992, p. 28). 
demanda de este producto era más amplio, al atraer no sólo a poblaciones limítrofes. Es así cuando vemos que la necesidad de madera procedente de los montes de Antequera lleva a vecinos de lugares más o menos lejanos a solicitar permiso para realizar talas en determinados puntos del término, lo que hace ver la importancia de tal actividad para los ingresos de las arcas municipales (Luchía, 2020, p. 321). De este modo ocurre con localidades cordobesas como Montilla, Lucena, Aguilar de la Frontera o La Rambla ${ }^{69}$, esta última a más de $80 \mathrm{kms}$ de distancia; o con las sevillanas de Osuna o Écija, a más de $90 \mathrm{kms}^{70}$.

En ocasiones las talas se realizaban de forma ilícita, por ejemplo, cuando vecinos de esas mismas localidades señaladas son sorprendidos cortándola y transportándola sin permiso; cuando se hacía en espacios no permitidos; o cuando afectaba a especies que se quería proteger, como fresnos, álamos, encinas o alcornoques ${ }^{71}$. Esto ocurría también en propiedades privadas, donde se internaban tanto vecinos como forasteros para sacar madera sin autorización del dueño ${ }^{72}$. En otros casos, incluso, se llegaba a situaciones tan picarescas como hacer acopio de madera que se hallaba ya "cortada e apilada" 73 . No faltan tampoco casos de corrupción, cuando la corta de árboles se hacía en zonas prohibidas con el consentimiento de los arrendadores de las penas del campo y de guardas, que no lo impiden, "dando liçençia...a otros que pudiesen cortar las maderas en logares de vedados... reçibiendo dádivas y cohechos" ${ }^{\text {" }}$.

El corcho de la corteza de los alcornoques era otro de los productos apreciados de la zona. Su recogida estaba limitada a una época del año concreta, entre finales de la primavera e inicios del verano. Servía como materia prima para zapateros y curtidores y se prohibía específicamente que se utilizase para techar las viviendas. También era un producto demandado por otras localidades como la ciudad de Granada o la población sevillana de Osuna ${ }^{75}$.

En entornos de monte bajo, el aprovechamiento observado se limitaba, cuando era posible, a la recogida de leña en zonas de abundantes lentiscos ${ }^{76}$ y a la recolección de esparto y recoba con destino artesanal. Esta última actividad era rematada por la ciudad al mejor postor y solía llevarse a cabo a finales de verano ${ }^{77}$.

69 AHMA, AACC, f. 2r, sesión de 21 de enero de 1494; f. 37v, sesión de 12 de diciembre de 1494; f. 95v, sesión de 23 de enero de 1496; AGS, RGS, 150012, 163.

70 AHMA, AACC, f. 81v, sesión de 23 de octubre de 1495; f. 95r, sesión de 15 de enero de 1496.

71 Como les sucede a vecinos mudéjares de la población de Olías (de Álora, Málaga) cuando son sorprendidos cortando madera de ribera, AHMA, AACC, f. 40r, sesión de 19 de diciembre de 1494; para otros ejemplos, f. 81v, sesión de 23 de octubre de 1495; y AGS, RGS, 150012, 163.

72 AHMA, AACC, f. 87r, sesión de 4 de diciembre de 1495.

73 AHMA, AACC, f. 67v, sesión de 28 de agosto de 1495.

74 AGS, RGS, 150112, 72.

75 AHMA, AACC, f. 13v, sesión de 15 de abril de 1494; f. 4, sesión de 30 de agosto de 1513; (Tejada Páez, 2005, I, p. 191).

76 AHMA, AACC, f. 58v, sesión de 24 de marzo de 1495.

77 AHMA, AACC, f. 24v, sesión de 29 de agosto de 1494 y f. 37v, sesión de 12 de diciembre de 1494. 


\section{LA FAUNA, OBJETO DE CAZA}

Asociada a toda esa vegetación que se va eliminando, recordemos, esos "montes bravos", toda una rica fauna, que debía ser frecuente en estas zonas, va ir desapareciendo, siendo las especies de gran porte las primeras en ser objeto de extinción. En la documentación analizada se señala la existencia de fieros animales que poblaban los montes con términos tales como "la caça", "malas alimañas", "salvaginas" y "otras cosas malas", que esconden la alusión a jabalíes, lobos, venados ${ }^{78}$ e incluso $\operatorname{osos}^{79}$. No faltaban tampoco otras especies de menor porte como conejos o codornices ${ }^{80}$. Con palabras similares se expresaba el Libro de la montería de Alfonso XI en el siglo XIV en relación con ese medio natural tildado de "peor andar" en áreas también del interior de Andalucía ${ }^{81}$, donde era habitual hallar los mismos tipos de animales de caza mayor, como el ciervo ${ }^{82}$.

Por otro lado, los restos óseos que se han podido estudiar procedentes del entorno periurbano de Antequera confirman la existencia de esas mismas especies como el lobo $^{83}$, el ciervo o el corzo $^{84}$, para el periodo anterior a la conquista castellana (1410), momento en el que más patente se reproduce en las fuentes escritas la idea de espacio estratégico de frontera para el territorio antequerano (Peláez Rovira, 2016 p. 158). A tales ejemplos se añaden el lince, el jabalí, el conejo y el erizo (Alonso Valladares y Garrido-García, 2015, p. 27) ${ }^{85}$. Las ordenanzas de la ciudad y las actas capitulares, ya en época castellana, mencionan como ejemplares habituales de caza de nuevo al conejo, la liebre, la perdiz y sus crías, los perdigones, y la tórtola ${ }^{86}$. Todo ello muestra, gracias a los estudios arqueológicos y al análisis de la documentación, la importancia de la actividad cinegética como complemento para la alimentación de la población, aprovechando las especies del entorno, tanto en época nazarí, como posteriormente.

Entre finales del siglo XV e inicios del XVI toda esa variada fauna era considerada como dañina por los vecinos, por lo que pasó entonces a ser objeto de

78 AHMA, LDR, f. 4v.

79 AGS, CC-P, leg. 2, s/f. Sobre la presencia histórica del oso y otras especies en latitudes tan meridionales de la península ibérica (Garrido-García, 2008).

80 AHMA, LRA, f. 110r

81 Como, por ejemplo, el entorno de Locubín (Jaén), los montes de Estepa (Sevilla), el término de Iznájar o el de Priego (Córdoba), (Alfonso XI, 1992, pp. 146, 169, 174, 176, 180, 204, 652, 662-663, 679, 683 y 684), todas ellas zonas de frontera en distintos puntos entre Granada y Castilla (Gozalbes Cravioto, 2006).

82 Una imagen similar es la que transmite J. Münzer tras la conquista de Granada durante su estancia en la que había sido hasta hace poco capital nazarí: "En los montes tiene tantos ciervos, osos, gamos, conejos y principalmente jabalíes que parece increíble" (Münzer, 1991, p. 46).

83 Los restos hallados de canis lupus podían referirse tanto a su versión doméstica, el perro, como al tipo salvaje (Alonso Valladares y Garrido-García, 2015, p. 24).

$84 \mathrm{El}$ segundo tipo animal más representado es el de los cérvidos, después de los ovicaprinos, (Ibidem, p. 27).

85 El consumo de erizo es mencionado por Ibn al-Jațīb en el siglo XIV (García Sánchez, 2011, p. 126, n. 19).

86 AHMA, Ordenanzas, ff. 55r-55v; AHMA, AACC, f. 5v. 
control y, por tanto, de obligada caza. Al mismo tiempo, como ya hemos señalado, se estaba produciendo la desaparición del monte, es decir, del ámbito natural de tales especies. Ya en 1494 uno de los motivos aducidos para desmontar los carrascales de la vega fue el peligro que los lobos, que ahí se guarecían, representaban para el ganado ${ }^{87}$, sobre todo al comprobar que ningún cazador estaba dispuesto a salir en su búsqueda, cuando en otras comarcas se les pagaba mejor por su captura, fuesen ejemplares adultos o camadas de lobeznos ${ }^{88}$. En otras ocasiones son los alguaciles con ayuda de agricultores y ganaderos los que tratan de limpiar el campo de estas alimañas ${ }^{89}$. De esta forma, se aprecian las medidas que se podían tomar para acabar con tales animales salvajes, terminar con su hábitat natural, al talar el espacio que les servía de refugio, y cazarlos. A su vez, ello provocaría su huida a sectores más resguardados, altos y alejados de la actividad humana, como las zonas de sierra.

Otras quejas vecinales también daban motivos para eliminar aquellos animales, como los daños que causaban en las cosechas, algo que vemos que ocurre cuando éstos se ven obligados a alimentarse en lugares que anteriormente habían estado ocupados por un monte ya perdido ${ }^{90}$. Una de esas especies consideradas dañinas era el conejo ${ }^{91}$, cuya carne, junto a la del venado o "carne de monte", podía ser consumida en los mesones de la ciudad ${ }^{92}$. Todas las piezas obtenidas en el monte eran pesadas en una tienda específica, establecida en Antequera ad hoc por el cabildo municipal ${ }^{93}$. Por su parte, las pieles eran aprovechadas por el pellejero de la ciudad $^{94}$.

De este modo, comprobamos cómo va desapareciendo cierto tipo de fauna que refleja un sistema ecológico concreto, necesario para su supervivencia (Alonso Valladares y Garrido-García, 2015, p. 32), sito en un amplio territorio, cuyas extensas masas forestales, no carentes de agua en las cercanías para su adecuado desarrollo, van a conocer una mayor presión antrópica.

87 AHMA, AACC, f. 13v, sesión de 15 de abril de 1494.

88 "a cabsa de los muchos lobos que avía en los términos de esta çibdad...no los avia gana de matar", AHMA, AACC, ff. 2rv, sesión de 21 de enero de 1494.

89 Así ocurre por orden del corregidor de la ciudad: "dixo un criador de ovejas que en el carrascal que está en la vega andavan lobos...perdieron todos los labradores e trabajadores de ganado su jornal...que no hallaron lobo ninguno", AGS, CC-P, leg. 2, s/f, 17 de febrero de 1514.

90 "senbrada se lo an comido la caça", AGS, CC-P, leg. 2, s/f.

91 "que por razón del daño que reçiben los labradores en los panes...que los caçen en todo el tienpo del año syn pena alguna", AHMA, AACC, f. 68v, sesión de 7 de septiembre de 1495.

92 A diferencia de las perdices que sólo podían adquirirse en el mercado, AHMA, AACC, f. 51r, sesión de 27 de enero de 1495 .

93 AHMA, AACC, ff. 29r y 31v, sesiones de 14 y 21 de octubre de 1494.

94 AHMA, AACC, f. 100v, sesión de 20 de septiembre de 1496. 


\section{EL AGUA}

El agua destaca como elemento clave para entender la dinámica del paisaje antes y después de la conquista castellana, en relación a la intensa ocupación del territorio ${ }^{95}$. Tanto su presencia como su ausencia son muestras del valor que poseen determinadas tierras para una población que busca y necesita destinarlas a un aprovechamiento diverso. Por ello, la reserva de agua en sí es considerada por los vecinos la clave por la cual un determinado terreno va a ser considerado útil y provechoso para sus cultivos y su ganado (González Villaescusa, 2002, p. 452). Esto se aprecia en zonas de sierra, donde "ay agua a cada parte" o en la propia vega antequerana, donde distintos pasajes señalan su abundancia mediante distintas fórmulas, siempre en plural, como "en medio de", "çerca de" o "junto con" las aguas. Cuando no era tan abundante, había que proteger su presencia, como podemos observar por medio de referencias a fuentes de vital importancia por constituir el único punto de abastecimiento para determinadas tierras, como sucede con la fuente de Santillán al noroeste de la ciudad ${ }^{96}$. Por ello, se trata de reservar el espacio más cercano a esos manantiales, impidiendo que fuese roturado y asegurando su acceso al ganado ${ }^{97}$.

Otra cuestión diferente es lo que ocurre con las tierras que carecen de agua y que son consideradas a priori de poco provecho y de mala calidad. Son aquéllas que coinciden con la mayor parte de terrenos concedidos para ser roturados, a lo cuales, de todas formas, había que dotarlos de agua. La falta o "defeto" de agua en superfi$\mathrm{cie}^{98}$ es un rasgo común de todos estos sectores caracterizados por ser "tierra estérile de agua", al hallarse alejados de las principales vías fluviales, lo que también aprecia algún autor local tiempo después, ante un paisaje que ya había sido transformado: "asta Genil, por ser más altas no alcanza el agua...donde se coje mucho trigo y zebada" (Tejada y Nava, siglo XVII, cap. III, s. p.).

La necesidad de agua en terrenos que iban a ser dedicados al secano supone un serio problema que los campesinos tratan de solventar con la búsqueda de aguas subterráneas y la creación de pozos y balsas, tal y como algunos vecinos señalan al hablar de "edefiçios para agua", de "cogedores de agua" y de "estancos", cuyo destino principal era abastecer al ganado de labor ${ }^{99}$. Para ello, la documentación revela

95 Así se considera en el estudio del paisaje que se realizó en el contexto del proyecto de trabajo sobre los Dólmenes de Antequera (Caballero Sánchez, 2011, p. 52); a nivel más general (Malpica Cuello, 1995-1998).

96 "en una legua e aun a legua media no ay...otra agua para vever, salvo aquella...e no tiene otra agua", AGS, CC-P, leg. 2, s/f.

97 AHMA, LRA, ff. 152v-154v; "por ser la dicha tierra fuerte e de mucha agua e madera e vellota e corchos, corteza e otras cosas...tiene neçesydad de mucho baldío e desenbargado en ella, porque aquella parte anda mucho ganado", AGS, CC-P, leg. 2, s/f.

98 "no ay fuente ni río ni agua"; "ninguna agua tiene que corra ni que mane"; "no ay agua ninguna de pie ni que mane", Ibidem.

99 "tierras donde no ay agua ninguna, salbo la que los dichos vezinos han fecho a mucha costa porque son muy fondos"; "quien no haze pozo se le pierde el ganado"; "an fecho pozos a su costa para abrevar sus ganados e que antes no lo solían tener ni tenían agua ninguna", Ibidem. 
el alto coste económico y de esfuerzo que se derivaba de la búsqueda de "lugares de agua" y de su extracción a través de pozos en aquellos puntos donde no existía. Era, en suma, una labor que formaba parte de los duros trabajos a realizar en los campos que se querían roturar, entre otras cuestiones, porque "se abren a mano". A ello hay que añadir la profundidad necesaria a alcanzar, los sondeos erróneos o la escasa cantidad de agua hallada, si atendemos a las palabras que muestran cómo los vecinos "sacan pozos":

hazen pozos e muy hondos e no hallan agua e tornar a lo hazer en otra parte e [a] mucha costa hallan al agua...con mucho travajo; este testigo tiene una roça e ha fecho en ella tres pozos que ha gastado más que vale la roça e no tiene agua para todo el año e asy han fecho los otros que tienen roças que sy pozos no hazen, todo no es nada...e no tiene agua en ellos; este testigo tiene un pedaço de roças e a gastado más de veynte mill maravedís e tiene fecho en ella muy poco e a gastado en pozos más de quatro mill maravedís e a començado abrir pozos en quatro partes e en la una de ellas con mucho travajo a hallado agua e asy an fecho todos los otros vezinos, porque allí tienen roças...an fecho pozos e muchos de ellos no tienen agua ${ }^{100}$.

\section{CONCLUSIONES: ¿OSOS ENTRE ALCORNOQUES?}

Hemos querido encabezar estas conclusiones con las dos especies registradas por la documentación entre finales del siglo XV e inicios del XVI, que pueden servir de indicadores de la transformación de un monte de caracteres típicamente mediterráneos. En ese mismo periodo de tiempo aún se constata su presencia y será el momento en el que comiencen a desaparecer del medio natural, de una manera más rápida en el caso de la fauna, más paulatina respecto a la vegetación.

Tras la conquista del territorio nazarí se iniciaron una serie de procesos, los repartimientos, con la intención de adaptar el espacio rural a las necesidades de la nueva sociedad castellana asentada, lo cual se hace más patente con el éxito repoblador que desembocó en un importante aumento demográfico. Esa adaptación trajo consigo la transformación del medio menos humanizado, que hemos delimitado en la comarca malagueña de Antequera, y que aparece como destacado foco de interés para otras poblaciones del centro de la actual comunidad autónoma de Andalucía. Las especies vegetales señaladas se relacionan con un medio natural diverso y dotado de contrastes. Por un lado, encontramos un monte bajo sobre suelos en proceso de degradación y, por otro, áreas boscosas de cierta densidad y sin falta de humedad, como muestra la presencia de quejigos o alcornoques.

La información analizada muestra que en cada fase del largo proceso de repartimiento se hace patente el acopio de más cantidad de tierras en sectores cada vez

100 Ibidem.

Anales de la Universidad de Alicante. Historia Medieval, núm. 22, 2021, pp. 81-103 
más alejados de la propia ciudad. El avance de la actividad humana por los entornos naturales, con el fin claro de obtener terrenos para el cultivo y para pastos, provocó que la fauna salvaje, que la usaba como refugio, pasara entonces a ser objeto de control por medio de la caza. Además, los espacios en retroceso de monte bajo y de áreas forestales pasaron a ser utilizados, a modo de establo natural, por especies domésticas como el cerdo o el vacuno.

La necesidad de mayor extensión de tierras para cumplir con las nuevas vecindades hace inevitable que se concedan zonas incultas, cuya roturación desvela que no siempre se hizo en beneficio de la comunidad, esquilmando áreas de destacado valor como fuente de aprovechamiento económico. Esto llevó a los vecinos a la defensa de áreas boscosas de cierta calidad que, en principio, el cabildo municipal estaba señalando para su destrucción y transformación en tierras de cultivo. Ello produjo una profunda mutación en el paisaje de forma irremediable, lo cual se logró con un gran esfuerzo y un alto coste económico a la hora de rozar estos espacios y poder aprovisionarlos de agua. Donde hasta entonces existía un monte variado en especies vegetales y animales, le siguió, al aplicar el sistema de rozas, la implantación de un campo especializado mayormente en un cultivo, el cereal. Tal fenómeno puede tener visos de especulación, quizás en relación con el reciente proceso de conquista española de América, lo cual habrá que ir comprobando por medio de la consulta de otro tipo de documentos que desvelen el destino concreto de la producción obtenida en esos campos. En definitiva, todo ello se traduce en un destacado cambio ecológico del paisaje, cuya imagen seguirá siendo transformada durante el periodo moderno y que es prácticamente desconocida para las poblaciones actuales.

\section{REFERENCIAS BIBLIOGRÁFICAS}

AlFONSO XI. (1992). Libro de la montería. Granada: Universidad de Granada.

Alijo Hidalgo, F. (1983). Antequera y su tierra: libro de repartimientos, 1410-1510. Málaga: Arguval.

Alonso Valladares, M. y Garrido-García, J. A. (2015). La explotación de los recursos cárnicos en la frontera del Reino Nazarí de Granada. Un estudio de caso en el yacimiento de La Moraleda (Antequera, Málaga). Revista del Centro de Estudios Históricos de Granada y su Reino, (27), 21-39.

BARCELó, M. (1988). La arqueología extensiva y el estudio de la creación del espacio rural. Arqueología medieval: en las afueras del "medievalismo" (pp. 195-274). Barcelona: Crítica.

Blanca López, G. (2009). Flora vascular de Andalucía Oriental. Sevilla: Junta de Andalucía.

Buxó, R. (2006). Paisajes culturales y reconstrucción histórica de la vegetación. Ecosistemas: Revista científica y técnica de ecología y medio ambiente, (15-1), 1-6. 
Caballero Sánchez, J. V. (Coord.). (2011). El paisaje en el Conjunto Arqueológico Dólmenes de Antequera. Sevilla: Junta de Andalucía.

CARMOnA Ruiz, M. A. (1995). Usurpaciones de tierras y derechos comunales en Sevilla y su "Tierra" durante el siglo XV. Madrid: Ministerio de Agricultura, Pesca y Alimentación.

Clemente Ramos, (2014). La sociedad rural en Medellín (c 1450-c 1550). Élites, labradores y pobres. Studia Historica. Historia Medieval, (32), 47-72. https://doi.org/10.14201/shhme2014324772

Cortina Ramos, A. y Queralt, A. (Coords.). (2007). Convenio Europeo del Paisaje: textos y comentarios. Madrid: Ministerio de Medio Ambiente.

FERNÁNDEZ PARADAS, M. (2004). Las respuestas generales del Catastro de Ensenada de Antequera (1753). Revista de Estudios Antequeranos, (14), 321-383.

GARCíA DE CORTÁZAR, J. A. (1988). Organización social del espacio: propuestas de reflexión y análisis histórico de sus unidades en la España medieval. Studia Historica. Historia Medieval, (6), 195-236.

García de Santamaría, A. (1982). Crónica de Juan II de Castilla. Madrid: Real Academia de la Historia.

GARCíA LATORRE, J. y GARCíA LATORRE, J. (1996). Los bosques ignorados de la Almería árida: Una interpretación histórica y ecológica. En A. Sánchez Picón (Col.), Historia y Medio Ambiente en el Territorio Almeriense (pp. 99-126). Almería: Universidad de Almería.

GARCía SÁNCHEZ, E. (2011). La alimentación de los andalusíes: Entre las normas médicas y la vida cotidiana. En J. M. Carabaza Bravo (Dir.), El saber en al-Andalus: textos y estudios, V. Homenaje a la profesora Dña. Carmen Ruiz Bravo-Villasante (pp. 121-134). Sevilla: Universidad de Sevilla.

GARRABOU, R. y NAREdo, J. M. (Eds.). (2008) El paisaje en perspectiva histórica: Formación y transformación del paisaje en el mundo mediterráneo. Zaragoza: Universidad de Zaragoza.

GARRIDO-GARCíA, J. A. (2008). Las comunidades de mamíferos del sureste de la Península Ibérica: Elementos para un análisis histórico. Galemys, (20/1), 3-46.

GÓMEZ MORENO, Ma L. (1989). La montaña malagueña: Estudio ambiental y evolución de su paisaje. Málaga: Diputación Provincial de Málaga.

GONZÁlez VillaescusA, R. (2002). Las formas de los paisajes mediterráneos. Jaén: Universidad de Jaén.

Gozalbes Cravioto, C. (2006). En torno a la primera frontera medieval de Antequera: las torres de frontera entre Antequera y Estepa. En F. Toro Ceballos, VI Estudio de Fronteras: población y poblamiento: homenaje a Manuel González Jiménez (pp. 313-324). Jáen: Diputación Provincial de Jaén.

Gozalbes Cravioto, C. (2015). Fuentes y métodos para el estudio de la frontera antequerana. Revista de Estudios Antequeranos, (18), 125-147. 
Guarnido Olmedo, V., (1977). La depresión de Antequera. Cuadernos de Geografía, (7), 39-70.

KirCHNER, H. (Ed.). (2010). Por una arqueología agraria: Perspectivas de investigación sobre espacios de cultivo en las sociedades medievales hispánicas. Oxford: Archaeopress. https://doi.org/10.30861/9781407305530

LuCHÍA, C. (2005). Propiedad comunal y dedicaciones productivas en el área concejil castellana bajomedieval. Studia Historica. Historia Medieval, (23), 275-295.

Luchía, C. (2020). Por que los montes de esta villa se conserben, e no se disipen como al presente estan: la regulación de los recursos forestales en la Corona de Castilla (siglos XIV-XVI). Espacio, tiempo y forma. Serie III, Historia medieval, (33), 303-332. https://doi.org/10.5944/etfiii.33.2020.25624

MalpiCa Cuello, A. (1993). Repoblaciones y nueva organización del espacio en zonas costeras granadinas. En M. A. Ladero Quesada, La incorporación de Granada a la Corona de Castilla. Symposium conmemorativo del V Centenario (pp. 513-558) Granada: Diputación Provincial de Granada.

Malpica Cuello, A. (1995-1998). Relaciones entre el medio físico y los campos de cultivo en el reino de Granada antes y después de la conquista castellana (siglos XIII-XVI). Cuadernos de Estudios Medievales y Ciencias y Técnicas Historiográficas, (21-23), 417-434.

Malpica Cuello, A. (1996). El paisaje vivido y el visto: Asentamientos y territorio en el Reino de Granada al final de la Edad Media. Arqueología Medieval, (4), $37-$ 58.

Malpica Cuello, A. (2000). La vida cotidiana. El paisaje rural nazarí. En $\mathrm{M}^{a} \mathrm{~J}$. Viguera Molins (Coord.), El Reino Nazarí de Granada (1232-1492): sociedad, vida y cultura. Historia de España Menéndez Pidal, VIII-IV (pp. 73-156). Madrid: Espasa-Calpe.

Malpica Cuello, A. (2009). El estudio del paisaje y la práctica de la arqueología del paisaje en el antiguo reino de Granada. Análisis de los paisajes históricos: de al-Andalus a la sociedad feudal. Granada: Alhulia.

MünZer, J. (1991). Viaje por España y Portugal: 1494-1495. Madrid: Polifemo.

Parejo, A. (2002). Una lectura simbólica de la Antequera barroca (fragmentos). Málaga: Unicaja.

Peláez Rovira, A. M. (2016). La imagen fronteriza de Antequera en los textos andalusíes. Anaquel de Estudios Árabes, (27), 151-167 https://doi.org/10.5209/rev_ANQE.2016.v27.47974

PÉrez Gallego, M. (1992). Antequera a fines del siglo XV. Málaga: Algazara.

PonZ, A. (1989). Viaje de España, 4. Madrid: Aguilar.

RODRigo COMINo, J. (2014). Los suelos de la provincia de Málaga: revisión y actualización de las fuentes edafológicas según la clasificación de FAO-WRB. Málaga: Universidad de Málaga. 
Rodríguez Molina, J. (2003). El personero: Portavoz y defensor de la comunidad ciudadana. Jaén; Diputación Provincial de Jaén.

Tejada y NaVA, F. (Siglo XVII). Historia de la ciudad de Antequera. [Manuscrito inédito].

Tejada PÁez, A. de (2005). Discursos históricos de Antequera. Málaga: Diputación Provincial de Málaga.

TORRES FonTES, J. (1972). La segunda campaña: Antequera 1410. Miscelánea de Estudios Árabes y Hebraicos. Sección Árabe-Islam, (21), 37-84.

TORRÓ, J. (2003). Arqueologia de la conquesta. Registre material, substitució de poblacions i transformació de l'espai rural valencià (segles XIII-XIV). En M. Barceló (Ed.), Feudalisme comptat e debatut: formació i expansió del feudalisme català (pp. 174-181). València: Publicacions de la Universitat de València (PUV).

TRILlo SAN JOSÉ, C. (1999). El paisaje vegetal en la Granada islámica y sus transformaciones tras la conquista castellana. Historia Agraria, (17), 131-152.

TRILlo SAN José, C. (2004). Agua, tierra y hombres en al-Andalus: la dimensión agrícola del mundo nazarí. Granada: THARG.

Zoido NARANJO, F. (2011). La dimensión paisajística de los conjuntos arqueológicos: aplicaciones y enseñanzas. En J. V. Caballero Sánchez (Coord.), El paisaje en el Conjunto Arqueológico Dólmenes de Antequera (pp. 12-23). Sevilla: Junta de Andalucía. 